Original Research Paper

\title{
Al-Qur'an Memorization Animation: Solusi Mudah Menghafal Al-Qur'an Pada Anak TPA Nurul Huda
} \author{
Hermoyo 5 \\ ${ }^{1}$ Universitas Muhammadiyah Surabaya, Surabaya, Indonesia \\ ${ }^{2}$ Universitas Muhammadiyah Surabaya, Surabaya, Indonesia \\ ${ }^{3}$ Universitas Muhammadiyah Surabaya, Surabaya, Indonesia \\ ${ }^{4}$ Universitas Muhammadiyah Surabaya, Surabaya, Indonesia \\ ${ }^{5}$ Universitas Muhammadiyah Surabaya, Surabaya, Indonesia
}

Uswatun Khasanah ${ }^{1}$, Riska Wahyuni ${ }^{2}$, Moh, Rusli ${ }^{3}$, Mochmammad Abhipraya Aryaputra ${ }^{4}$, R. Panji

https://doi.org/10.29303/jpmpi.v3i2.969

Sitasi: Khasanah, U., Wahyuni, R., Rusli, M., Aryaputra, M. A \& Hermoyo, R. P. (2021). Al-Qur'an Memorization Animation: Solusi Mudah Menghafal Al-Qur'an Pada Anak TPA Nurul Huda. Jurnal Pengabdian Magister Pendidikan IPA, 4(3)

\section{Article history}

Received: 30 Agustus 2021

Revised: 17 September 2021

Accepted: 18 September 2021

*Corresponding Author: Uswatun Khasanah, Universitas Muhammadiyah Surabaya, Surabaya, Indonesia. Email: uswatunkhasanah12032001@gmail.com.

\section{Pendahuluan}

$\mathrm{T}$ aman pendidikan Al-Qur'an atau biasa disingkat TPA merupakan lembaga pendidikan nonformal berupa pengetahuan agama islam. Dalam Peraturan Pemerintah Republik Indonesia Nomor 55 Tahun 2007 menyebutkan bahwa tujuan TPA adalah meningkatkan kemampuan peserta didik dalam membaca, menulis, memahami, dan mengamalkan kandungan Al-Qur'an pada anak usia taman kanak-kanak, sekolah dasar atau madrasah

\begin{abstract}
TPA has a goal to improve students' ability to read, write, understand and practice the Qur'an. At TPA Nurul Huda, which is located in Bendo Hamlet, RT 03, RW 04, Karanganyar Village/Subdistrict, Ngawi Regency has a problem, namely the low memorization ability of students. This is caused by several factors, including the heterogeneity of children's ages between 5 and 12 years, unattractive media and teachers who have difficulty finding ways to improve children's ability to memorize the Qur'an. The purpose of this community service PKM activity is to provide solutions to the problems experienced by TPA Nurul Huda. The solution given is an animated video learning media called Al-Qur'an Memorization Animation. Service activities are carried out for 4 months starting from June to September 2021. The methods used in this service are socialization, training (implementation), mentoring, measurement, and regeneration. The result of this activity is that the children of TPA Nurul Huda experienced a significant increase in memorizing the Qur'an as indicated by the pretest and posttest assessments.
\end{abstract}

Keywords: tpa nurul huda, improving memorization skills, al-qur'an memorization animation

ibtidaiyah (6-12 tahun). Lembaga pendidikan AlQur'an memiliki peran yang penting untuk mempersiapkan anak menjadi pribadi yang Qurani dan menjadikan Al-Quran sebagai pedoman dalam kehidupannya.

TPA Nurul Huda merupakan TPA yang diselenggarakan oleh pengurus Masjid Nurul Huda dibawah naungan Lembaga Pembinaan Pengembangan TK Al-Qur'an Badan Komunikasi Pemuda Remaja Masjid Indonesia (LPPTKABKRMI) Kabupaten Ngawi. TPA Nurul Huda berlokasi di Dusun Bendo, RT 03, RW 04, 
Desa/Kecamatan Karanganyar, Kabupaten Ngawi. TPA Nurul Huda mempunyai satu orang pengajar dan terdapat tiga pengurus yaitu terdiri atas kepala, sekretaris dan bendahara. Siswa-siswi TPA berjumlah 15 anak dengan 4 orang anak laki-laki dan 11 anak perempuan.

TPA Nurul Huda memiliki sebuah permasalahan yaitu kemampuan hafalan yang dimiliki oleh siswa-siswinya sangat rendah. Hal ini diketahui langsung dari guru TPA Nurul Huda yang mengeluhkan permasalahan tersebut. Sebagai tindak lanjutnya dilakukan wawancara dengan kepala TPA Nurul Huda. Dari hasil wawancara diketahui bahwa 10 dari 15 anak memiliki kemampuan hafalan yang rendah. Hal ini terjadi disebabkan oleh oleh tiga faktor. Faktor pertama adalah usiaanak TPA Nurul Huda yang heterogen dengan rentan usia 5 s.d. 12 tahun. Faktor keduaadalah media pembelajaran yang kurang menarik bagi anak usia 5 s.d 12tahun,hal ini terjadi dikarenakan guru hanya memberikan media pembelajaran sederhana berupa buku Juz Amma. Serta factor ketiga guru mengalami kesulitan dalam mencari cara untuk meningkatkan hafalan anak.

PembelajaranTPA dapat dilakukan melalui pendekatan klasikaldan privat yang disesuaikan dengan kondisi kesiapan anak dalam memperolehpelajaran yang disebabkan oleh usia anak TPA yang heterogen antara 5 s.d. 12 tahun. Metode pembelajaran disesuaikan dengan usia perkembangan anak dengan memperhatikan cara belajaranya yaitu dengan cara belajar sambil belajar, sehingga anak tidak mudah bosan dalam proses belajar.Media pembelajaran yang akan digunakan sebaiknyamenarik danmenyenangkan bagi anak serta memenuhi unsur keindahan dan keunikan sehingga dapat meningkatkan kemampuan berfikir dan kreativitas anak. Dari hal ini maka dibutuhkannya media pembelajaran baru yang dapat meningkatkan kemampuan hafalan siswa-siswi TPA Nurul Huda. Media ini dapat diaplikasikan dalam proses pembelajaran di TPA.

Media pembelajaran yang dapat meningkatkan kemampuan anak dapat berupa apapun salah satunya adalah film animasi. Film animasi saat ini menjadi media pembelajaran yang efektif digunakan pada anak usia dini. Tokoh animasi yang lucu dapat meningkatkan minat dan semangat anak dalam proses pembelajaran berlangsung. Dalam penelitian (Tuti, 2016) tentang Penggunaan Film Dora the Eksploarer menyebutkan bahwa film animasi dora efektif dalam meningkatkan kemampuan kosa kata pada anak. Dan dalam penelitian (Ginting, Putra and Negara, 2017) tentang Pengaruh Penerapan Model Pembelajaran Quantum Menggunakan Media Film Animasi Terhadap Perkembangam Kemampuan Kosakata Pada Anak Kelompok B juga meningkatkan kemapuan kosa kata pada anak PAUD Kusuma 2 Denpasar dan TK Buana Kumara Asih Denpasar.

Dari permasalahan yang dimiliki oleh TPA Nurul Huda dan beberapa penelitian yang ditemukan maka solusi yang tepat untuk meningkatkan kemampuan hafalan siswa-siswi TPA Nurul Huda adalah dengan memberikan media pembelajaran berupa film/video animasi. Video animasi dibuat dengan unik agar dapat membangkitkan semangat siswa-siswa TPA Nurul Huda dalam proses pembelajaran. Konten video animasi dibuat menggunakan metode yang efektif. Dalam penelitian (Safa'at and Inayati, 2019) tentang Efektifitas Metode Tikrar Dan Talqin Dalam Meningkatkan Pembelajaran Al-Qur'an menyebutkan bahwa metode tikrar dan talqin sangat efektif dalam meningkatkan pembelajaran Al-Qur'an di kelas 7 D ditunjukkan 17 dari 28 sisawa berhasil mencapai target hafalan. Sedangkan dalam penelitian (Solong and Jazimi, 2020) tentang Efektivitas Metode Murojaah Dalam Kegiatan Tahfidz Al-Qur'an Di Pondok Pesantren AlMuttaqiin Taki Nioda Kota Gorontalo menyebutkan bahwa efektivitas hasil terlihat dalam satu tahun santri sudah mencapai target 10 Juzhafalan Al-Qur'an setelah menerapkan metodemuroja'ah dalamkegiatan tahfidz Al-Qur'an sehingga 3 tahun mencapai hafalan 30 Juz. Dari rujukan beberapa penelitian ini maka metode yang dipilih adalah talqin (membacakan ayat dan ditirukan), tikrar (membacakan ayat secara berulang) dan murojaah (pengulangan hafalan dari ayat yang telah dihafalkan). Metode ini bisa disingkat dengan sebuatan metode $2 \mathrm{~T}+1 \mathrm{M}$.

Media pembelajaran video animasi dibuat dengan nama Al-Qur'an Memorization Animation yang memiliki tokoh animasi yakni Hafizh dan Hafizhah. Media pembelajaran ini dibuat dengan 
tujuan untuk mengatasi kesulitan anak dalam menghafal Al-Qur'an Juz 30 melalui media pembelajaran menghafal Al-Qur'an sehingga dapat memudahkan anak menghafal Al-Quran Juz 30 dengan baik. Selain itu mengenalkan media pembelajaran Al-Qur'an Memorization Animation untuk dapat diaplikasikan dalam pembelajaran di TPA Nurul Huda. Selain tujuan pembuatan media pembelajaran terdapat juga manfaat kegiatan pengabdian ini yaitu memberikan edukasi pada orang tua anak dan guru mengenai media pembelajaran menghafal Al-Qur'an Juz 30 yang mudah bagi anak agaranak di TPA Nurul Huda dapat secara mudah menghafalkan dan memahami Al-Qur'an Juz 30.

Potensi dari pengaplikasian media pembelajaran Al-Qur'an Memorization Animation ini meliputi setelah pembelajaran menggunakan media pembelajaran Al-Qur'an Memorization Animation maka siswa-siswi TPA Nurul Huda dapat menghafal Al-Qur'an dengan cepat dan mudah, meningkatkan kemampuan siswa-siswi TPA Nurul Huda dalam menghafal Al-Qur'an khususnya juz 30 dan, menjadikan TPA Nurul Huda sebagai contoh TPA lain dalam peningkatan kemampuan hafalan Al-Qur'an khususnya juz 30 pada siswa-siswinya. Selain itu juga dapat meningkatkan kepercayaan masyarakat terhadap kualitas pendidikan TPANurul Huda.

\section{Metode}

Pelaksanaan pengabdian ini dilakukan di TPA Nurul Huda. Program pengabdian ini dilakukan selama empat bulan dari bulan Juni hingga September 2021. Kegiatan ini merupakan bentuk pengabdian masyarakat yang dilakukan oleh tim pekan kratif mahasiswa pengabdian masyarakat (PKM PM) dari Universitas Muhammadiyah Surabaya. Kegiatan ini bentuk dari realitasi proposal yang lolos mendapat dana hibah dari Dikti. Lokasi TPA Nurul Huda berada di Dusun Bendo, Kecamatan Karanganyar, Kabupaten Ngawi Provinsi Jawa Timur pada bulan Juni hingga September. Lokasi TPA Nurul Huda berbatasan langsung dengan Provinsi Jawa Tengah, dimana apabila ke utaraberbatasan langsung dengan Kabupaten Blora dan apabila ke barat berbatasan langsung denganKabupaten
Sragen. Butuh waktu 1 jam jarak tempuh dari pusat kota untuk ke mitra ini dengan menggunakan kendaraan umum. Namun, jika sudah mendekati lokasi hanya ada satu transportasi umum yaitu ojek yang berada diterminal gandingan.

Penduduk di lokasi TPA Nurul Huda memiliki mata pencaharian sebagai petani. Dalam hal ini penduduk atau masyarakatnya ada yang memiliki kebunsendiri dan ada juga menggunakan kebun milik PERHUTANI. Selain itu juga banyakmasyarakat yang mengadu nasib dikotakota besar dan luar pulau jawa yang bekerja sebagai kuli bangunan, penambang emas, penjual jamu dan sebagainya. Latar belakang pendidikan masyarakat adalah lulusan SD dan SMP. Hal tersebut disampaikan oleh pengurus TPA Nurul Huda yaitu Supriyanto. Selain itu sangat sedikit sekali masyarakat yang memiliki latar belakang pendidikan agama, dan sedikit sekali masyarakat yang memiliki keinginan serta tekad melanjutkan Pendidikan tinggi setelah tamat dari Sekolah Menengah Awal. Hal tersebut berpengaruh terhadap kemampuan anak-anak di daerah ini. Keterbatasan pengetahuan dan minat belajar yang dimiliki oleh orang tua menjadikan mereka kurang mendukung anaknya dalam pendidikan khusunya pendidikan agama.

Adanya permasalahan dari TPA Nurul Huda maka disolusi yang diberikan adalah menciptakan media pembelajaran video animasi Al-Qur'an Memorization Animation. Video animasi ini dapat diaplikasikan dalam pembelajaran di TPA Nurul Huda. Tahap awal kegiatan pengabdian ini adalah melakukan koordinasi sebagai bentuk komunikasi awal pelaksanaan pengabdian yang akan segera dilakukan. Sebelumnya pihak tim PKM PM juga telah melakukan wawancara sebagai bentuk pengumpulan data. Setelah kegiatan ini resmi dilaksanakan maka tahap pertama yang dilakukan adalah sosialisasi pengenalan media pembelajaran kepada pengurus, guru dan juga siswa-siswi TPA Nurul Huda. Tahap kedua adalah pelatihan penggunaan media (implementasi oleh tim) kepada pengurus, guru dan juga siswa-siswi TPA 
Nurul Huda. Tahap ketiga pengaplikasian media dalam proses pembelajaran mandiri di TPA Nurul Huda oleh guru dan siswa-siswi dengan pengukuran berupa pretes dan posttes. Tahap keempat adalah pendampingan IPTEK untuk evaluasi dan monitoring pembelajaran secara mandiri oleh TPA Nurul Huda secara berkala. Tahap kelima implementasi kedua oleh tim untuk mengukur peningkatan kemampuan siswa-siswi TPA Nurul Huda setelah menggunakan media pembelajaran Al-Qur'an Memorization Animation. Tahap keenam kaderisasi kepada tutor sebaya dan perwakilan guru untuk keberlanjutan program. Tahap ketujuan pendampingan IPTEK kader dan pelatihan kepada kader untuk melakukan evaluasi dan monitoring lanjutan dan pelatihan penggunaan media dengan kreatif.

Alat dan bahan yang diperlukan dalam pembuatan media pembelajaran adalah aplikasi editing yang terdiri dari photoshop, flipaclip dan kine master. Alat dan bahan yang digunakan untuk pembelajaran adalah gawai/laptop dan lembar penilaian. Pengukuran yang dilakukan dengan acuan lembar pretes dan posttes. Pengukuran ini memiliki beberapa kriteria penilaian tertentu. Pemerolehan data dapat dilakukan dalam proses pembelajaran yang dilakukan secara mandiri oleh TPA Nurul Huda terdapat penilaian pretes yang dilakukan sebelum pembelajaran menggunakan video animasi Al-Qur'an Memorization Animation. Setelah pembelajaran dilakukan terdapat penilaian postes yang diterapkan dengan pembelajaran lain berupa hafalan sholat, kuis, cerita inspiratif, sambung ayat dan setor hafalan. Pengukuran juga dilakukan oleh tim secara langsung dengan melakukan pendampingan IPTEK bersama guru untuk mengetahui tingkat keberhasilan program.

\section{Hasil dan Pembahasan}

Kegiatan pengabdian ini dimulai dengan sosialiasi media untuk mengenalkan isi dan konsep media pembelajaran video animasi Al-Qur'an Memorization Animation kepada mitra yang dilakukan pada tanggal 26 Juni 2021 melalui zoom meeting. Kegitan ini dihadiri oleh pengurus, guru, dan siswa-siswi TPA Nurul Huda. Dari kegiatan ini pihak TPA Nurul Huda dapat memahami isi, konten dan konsep video animasi $A l$ Qur'anMemorizationAnimation.

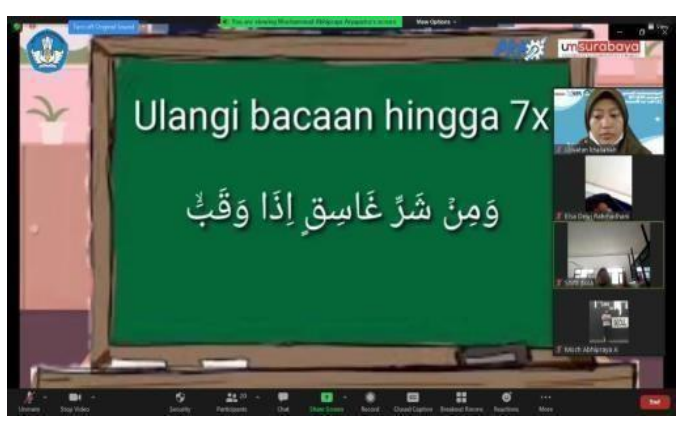

Gambar 1 Sosialisasi

Kegiatan yang kedua adalah implementasi oleh tim yang pertama. Kegiatan ini dilaksanakan untuk memberikan pelatihan kepada pihak TPA Nurul Huda mengenai penggunaan media pembelajaran Al-Qur'an Memorization Animation dengan efektif. Kegiatan ini dilaksanakan pada tanggal 3 Juli 2021 melalui zoom meeting. Dari kegiatan ini pihak TPA dapat mengetahui cara penggunaan media pembelajaran dengan mudah dan efektif.

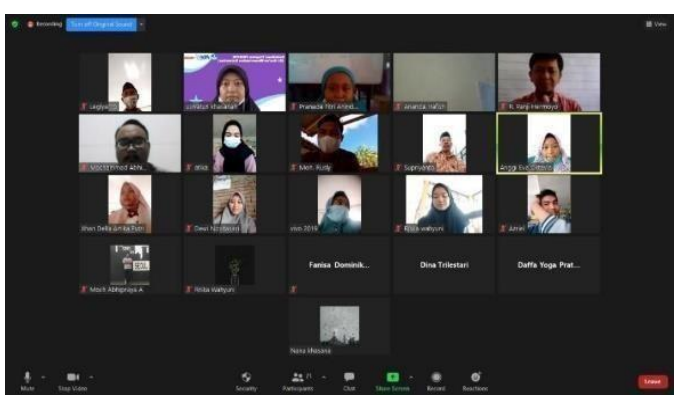

Gambar 2 implementasi

Kegiatan yang ketiga adalah pengaplikasian media pembelajaran video animasi Al-Qur'an Memorization Animation di TPA Nurul Huda atau implementasi mandiri sudah berjalan selama satu setengah bulan. Pengaplikasian ini berupa pembelajaran secara mandiri yang 
dilakukan oleh TPA Nurul Huda. Jadwal pembelajaran di TPA Nurul Huda menggunakan media pembelajaran video animasi Al-Qur'an Memorization Animation adalah satu minggu tiga kali yaitu hari Minggu, Rabu dan Jumat. Pembelajaran diawali dengan pengukuran berupa pretes. Siswa-siswi TPA dapat melakukan tes hafalan secara bersama-sama ataupun secara mandiri yang kemudian guru dapat melakukan penilaian. Hafalan dimulai dari surat yang sering didengar oleh masyarakat umum yaitu suarat AnNas.

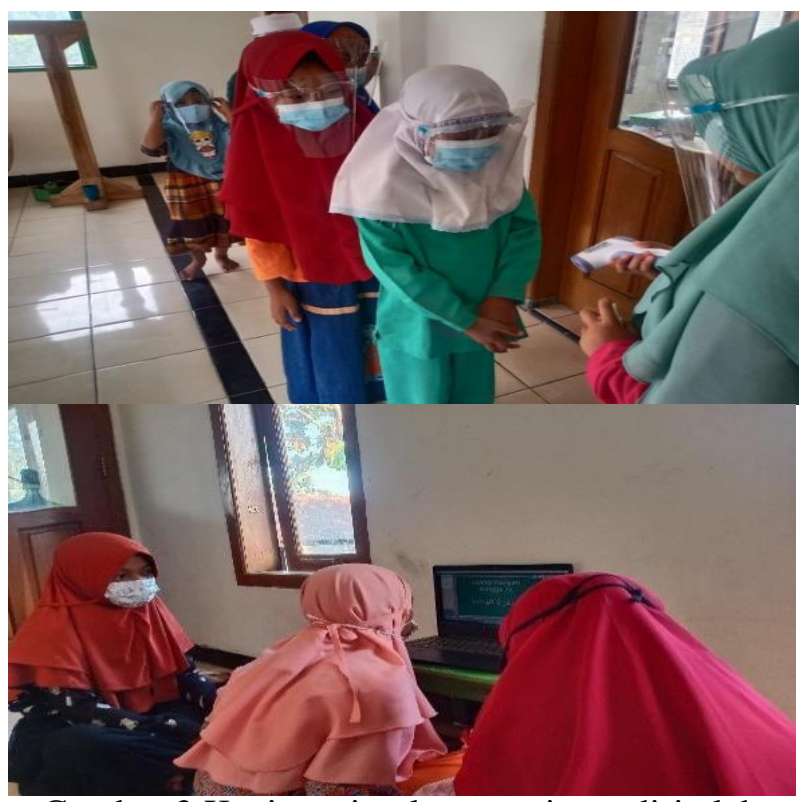

Gambar 3 Kegiatan implementasi mandiri oleh pihak TPA Nurul Huda

Kegiatan yang keempat adalah pendampingan IPTEK. Kegiatan ini dilakukan oleh guru dan TIM PKM untuk melakukan evaluasi dan monitoring terhadap pembelajaran yang telah dilaksanakan secara mandiri. Dari kegiatan ini tim PKM dapat melihat hasil penilaian yang telah dilakukan oleh guru. Hasil penilaian ini menjadi bahan evaluasi untuk tim dan guru. Hasil kegiatan ini adalah guru dapat melakukan meningkatkan pembelajaran di TPA Nurul Huda berdasarkan hasil evaluasi yang telah dilaksanakan. Pendampingan IPTEK dilakukan satu minggu sekali. Kegiatan telah dilaksanakan tiga kali pada pada tanggal 24 Juli, 2 agustus dan 9 agustus.
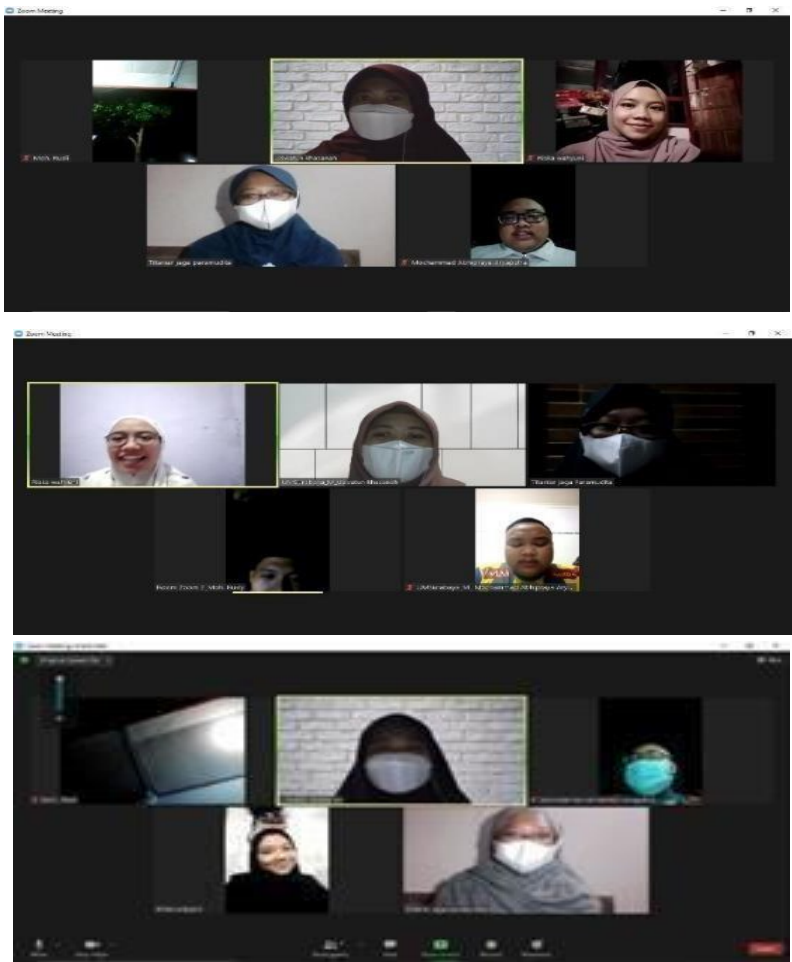

Gambar 4 Kegiatan pendampingan IPTEK

Kegiatan yang kelima adalah implementasi kedua oleh tim merupakan kegiatan yang dilakukan untuk mengukur peningkatan kemampuan siswa-siswi TPA Nurul Huda dalam menghafal Al-Qur'an menggunakan Al-Qur'an Memorization Animation secara langsung dengan memberikan tes hafalan berupa sambung ayat. Kegiatan implementasi ini dilaksanakan pada tanggal 15 Agustus 2021 melalui zoom meeting. Hasil dari kegiatan ini adalah terdapat peningkatan yang signifikan terhadap kemampuan hafalan yang dimiliki siswa-siswi TPA Nurul Huda dengan mengaju pada hasil pretes dan postes.

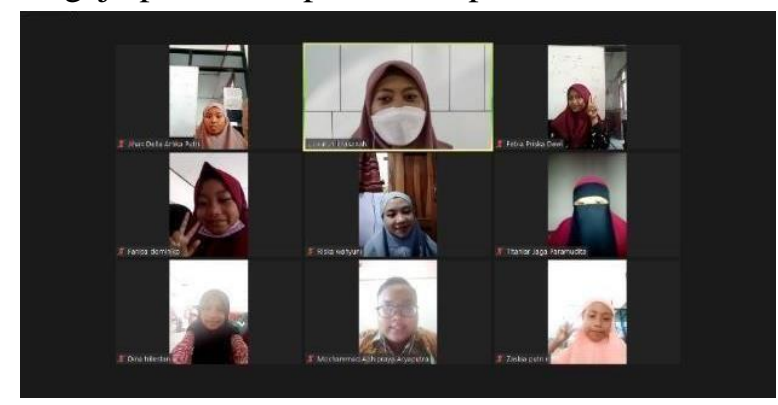

Gambar 5 Kegiatan implementasi kedua 
Kegiatan yang keenam adalah kaderisasi. Kegiatan ini adalah pembentukan kader program Al-Qur'an Memorization Animation. Kader ini dibentuk dari perwakilan siswa yang disebut dengan tutor sebaya dan juga perwakilan guru. Kader tutor sebaya dipilih dari siswa/siswi yang memiliki usai tinggi, hal ini dilakukan agar kader dapat melakukan pengarahan kepada teman-teman yang memiliki usai dibawahnya.Kaderisisasi dilakukan secara daring pada tanggal 22 agustus 2021. Hasil dari kegiatan ini adalah terbentuknya kader Al-Qur'an Memorization Animation yang dapat melakukan keberlanjutan program.
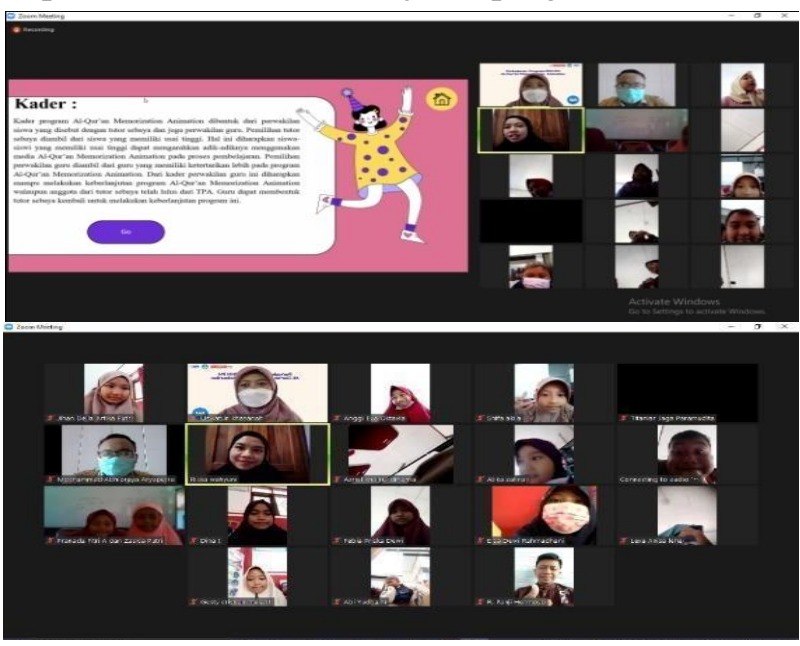

Gambar 6 Kegiatan kaderisasi

Kegiatan yang ketujuh adalah pendampingan IPTEK dengan kader dan pelatihan merupaka kegiatan evaluasi dan monitong dari kegiatan implementasi mandiri oleh mitra. Selain itu terdapat pelatihan menggunaan media pembelajaran agar pembelajaran di TPA dapat ditingkatkan kembali. Kegiatan ini dilakukan pada tanggal 27 agustus 2021.

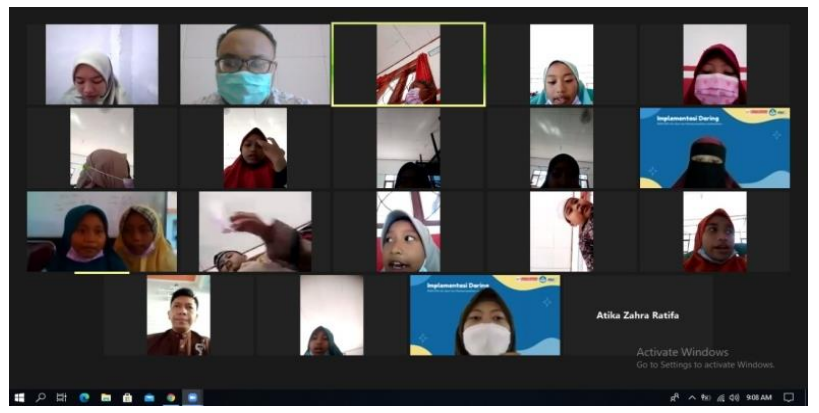

Gambar 7 Kegiatan pendampingan IPTEK dan pelatihan kader

Dari keseluruhan pelaksanaan program diketahui bahwa 15 anak TPA Nurul Huda mengalami peningkatan kemampuan dalam menghafal diketahui dari hasil pengukuran pretes dan posttes. Berikut diagram yang menggambarkan adanya peningkatan yang signifikan.

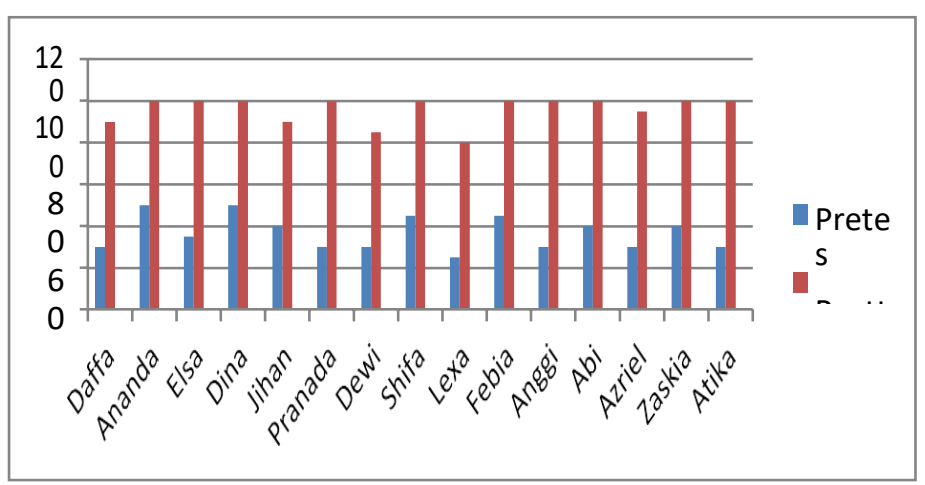

Gambar 8 Diagram hasil pretes dan postes

Dari hasil peningkatan ini dapat diketahui bahwa penggunaan media pembelajaran video animasi Al-Qur'an Memorization Animation menjadi solusi yang tepat untuk meningkatkan kemampuan anak dalam menghafal Al-Qur'an. Dengan peningkatan yang signifikan ini diharapkan media pembelajaran Al-Qur'an Memorization Animation dapat digunakan secara baik dengan melakukan keberlajutan pembelajaran di TPA Nurul Huda. Selain itu TPA Nurul Huda juga dapat menjadi alternatif yang tepat sebagai tempat belajar Al-Qur'an dengan mudah, cepat dan menyenangkan. Kemanfaatan dari kegiatan ini adalah meningkatkan kualitas pendidikan TPA Nurul Huda dan masyarakat disekitar lokasi TPA. Selain itu peningkatan minat belajar bagi anakanak di Dusun Bendo,Kecamatan Karanganyar, Kabupaten Ngawi dan peningkatan dukungan para orang tua dalam proses pembelajaran.

\section{Kesimpulan}

Dari kegiatan pengabdian ini telah diciptakannya media pembelajaran baru berupa video animasi Al-Qur'an Memorization Animation 
yang dibuat oleh tim PKM untuk solusi peningkatan kemampuan hafalan siswa-siswi TPA Nurul Huda. Pengaplikasian media pembelajaran ini dilakukan secara langsung pada pembelajaran di TPA. Adanya media pembelajaran baru ini bisa meningkatkan kemampuan hafalan siswa-siswi TPA Nurul Huda diketahui dari hasil pretes dan postes yang telah dilakukan. Dengan adaya media pembelajaran video animasi Al-Qur'an Memorization Animation juga meningkatkan kualitas pendidikan agama di Dusun Bendo, Kecamatan Karanganyar, Kabupaten Ngawi khusunya di TPA Nurul Huda.

\section{Saran}

Dalam kegiatan pengabdian masyarakat dan penyusunan artikel ini pastinya masih banyak kekurangan. Semoga kegiatan selanjutnya dapat lebih diperbaiki lagi.

\section{Ucapan Terima Kasih}

Ucapan terima kasih disampaikan kepada pihak yang telah terlibat dan membantu dalam kegiatan pengabdian masyarakat ini. Ucapan terima kasih kepada:

1. Kepala, pengurus dan guru TPA Nurul Huda

2. Siswa-siswi TPA Nurul Huda

3. Masyarakar Dusun Bendo, Desa/Kecamatan Karanganyar, Kabupaten Ngawi

4. BAKAI (Biro administrasi kemahasiswaan alumni dan inovasi) Universitas Muhammadiyah Surabaya

5. Dosen pembimbing PKM PM

6. DIKTI (Direktorat Jenderal Pendidikan Tinggi Kementrian Pendidikan, Kebudayaan, Riset dan Teknologi)

\section{Daftar Pustaka}

Ginting, T. B., Putra, I. K. A. and Negara, I. G. A. O. (2017) 'Pengaruh Penerapan Model Pembelajaran Quantum Menggunakan
Media Film Animasi Terhadap

Perkembangan Kemampuan Kosakata

Pada Anak Kelompok B', Jurnal

Pendidikan Anak usia Dini Universitas

Pendidikan Ganesha, 5(1), pp. 1-10.

Safa' at, M. K. and Inayati, N. L. (2019) 'Efektivitas Metode Tikrar Dan Talqin Dalam Meningkatkan Pembelajaran Al-Qur'an', pp. 79-83.

Solong, N. P. and Jazimi, I. (2020) 'Efektivitas metode muraja', ah dalam kegiatan tahfidz al-qur' an di pondok pesantren almuttaqiin taki niode kota gorontalo', 16, pp. 96-114.

Tuti, N. L. E. (2016) 'Keefektifan penggunaan media film Dora the Explorer dalam meningkatkan kosakata anak di kelompok bermain Tamanku Yogyakarta', Jurnal Pendidikan Guru Pendidikan Anak Usia Dini, 1, pp. 105-116. 